Quinn, K. (2014). Google and the Culture of Search. [Review of the book Google and the Culture of Search, by K. Hillis, M. Petit \& K. Jarrett]. Journal of Broadcasting \& Electronic Media 58(3), 475-477. doi:10.1080/08838151.2014.935943

\title{
Google and the Culture of Search
}

Hillis, K., Petit, M., \& Jarrett, K. (2013). Google and the Culture of Search. New York: Routledge. 240 pages.

"What did you do before Google?" This provocative question forces me to pause and reflect on a not-so-distant past set of practices related to how we acquire knowledge and find answers. For some, life before Google is hard to recollect, because it has become so central to how we answer questions. In asking this question of others, tools such as Dogpile and AltaVista may surface as suggestions; some will name such antiquated resources as the library card catalog drawers or the Reader's Guide to Periodicals Index. For almost anyone who is able to answer the question, there is a sharp recognition that so very much has changed in a seemingly short time. Debate sometimes flares up on whether Google has made us more stupid or smarter (e.g., Carr, 2010 and Anderson \& Rainie, 2010); organizations of state have resisted Google's monopolistic role (Lohr, 2012; Kanter \& Pfenner, 2010); and a whole generation of information seekers, the "Google generation," is reported to have acquired a different orientation to learning (Gunter, Rowlands \& Nicholas, 2009). There is ample evidence that Google has decidedly altered the ways in which we gain access to information, but just how much has changed? Authors Ken Hillis, Michael Petit and Kylie Jarrett take a deep dive into this question with Google and the Culture of Search (2013, Routledge) and examine Google's place in a long history of mankind's quest for a source of universal knowledge.

In a true spirit of neo-liberal critique, Hillis, Pettit and Jarrett dare to pair the first principles of metaphysics with conceptual elements of Bordieu's field theory (1993), and situate Google at a powerknowledge nexus. The authors argue that, when viewed through a metaphysical lens, the everyday material practices of today's Google-ers intersect with a primal and mystical search for "truth." Morever, they maintain that Google has been elevated to a consecrated status, due in part to its foundation in the Californian ideology and continual mantra of "Don't be evil," a status that accords Google considerable power and symbolic capital. This forms a theology that fundamentally grounds the way we in which we engage, experience, and understand our social reality, and predisposes us to an expectation for instant answers to complex questions. The authors propose, if somewhat despairingly, that Google's version of truth, which utilizes the concept of relevance as the guiding metric for surfacing knowledge and preferences an algorithmically-driven mining of past interactivity, provides a radical preEnlightenment predisposition toward using history as a guide to resolve future concerns, and may result in a dearth of hope and plethora of old solutions to new challenges.

The strength of this work lies in its copious and meticulous detail, which provides a firm basis for the authors' arguments. Hillis, Petit and Jarrett take the reader on an historical journey through the intertwined ideas of knowledge automation and the search for truth, conveying the reader through the philosophical roots of Atomism and Neo-Platonism, to panpsychic visions of a universal library and HiveMind, and culminating at the relatively modern depictions of a World Brain and Universal Electronic Library. They chronicle the attendant practices of knowledge management, ranging from Renaissance incursions into combinatory analysis to Bush's articulation of the Memex. Background sketches of the modern visionaries Eugene Garfield, Vanvear Bush, Manfred Kochen and J. C. Licklider, profiled as information scientists-cum-metaphysicians, provide a satisfying and comprehensive portrayal of the metaphysical journey toward truth. Yet, the detailed prose, rich with metaphysical concepts, also makes this work challenging and somewhat inaccessible for readers without advanced grounding in philosophy. It is a dense work, and the authors compound this hindrance by their pursuit of tangents and commentary not directly related to their arguments. An example can be found in their allusions to 
hagiography and the death of Steve Jobs in support of a contention that Google is sufficiently powerful to interpret law to its own ends (p. 171).

Interestingly too, despite its significance to the authors' arguments, discussion of the political economy of the search culture of did not benefit from a comparable level of detail. For example, the advertising model of media sustenance was treated in brevity, and few observations were offered on how this funding mechanism shapes the experience and reality of information search. Likewise, the accumulation of personal data across Google's many platforms contributes to a new configuration of knowledge capture, in addition to providing enhanced opportunities for economic realization. The dimensions and implications of these activities deserve more exploration, not only due to their impact on how "knowledge" is conceived but also because exploitation of such knowledge holds weight for how questions are answered and "truth" is experienced.

The authors conclude with a noteworthy salvo to the academy, which is perhaps the most important take away of this work. They perceive that the denial of connection between the spheres of metaphysics and political economy has led us to miss the significance of according a private, for-profit entity with metaphysical power. Thus, they call for "a reformulation of a political economy of metaphysics" (p. 203) to attend to how technologies that order our sense of space, identity, time and change might be transposed by capitalism. Though pointed directly at neoliberalism, their assertion should be stimulation for discussion in many fora. Technologies, and particularly information and communication technologies, are vehicles through which we make meaning in our everyday, ordinary lives. But the forces guiding these often for-profit ventures encourage exploitation of the ritualistic and mystical dimensions of their use. Critical reflection on how these technologies shape, color and guide our understanding of self, as well as our everyday reality, is a moral imperative. Perhaps, as these authors argue, it is the principle challenge of our time.

Kelly Quinn (PhD, University of Illinois at Chicago) is a Clinical Assistant Professor in the Department of Communication at the University of Illinois at Chicago. Her work focuses on new media and its intersection with the life course, social capital, friendship and privacy.

Anderson, J. \& Rainie, L. (19 Feb 2010). Future of the Internet IV. Washington, DC: Pew Internet \& American Life Project. Available at http://www.pewinternet.org/Reports/2010/Future-of-theInternet-IV.aspx

Bourdieu, P. (1993). The Field of Cultural Production: Essays on Art and Literature (R. Johnson, ed.). Cambridge, UK: Polity.

Carr, N. (2010). The Shallows: What the Internet is Doing to Our Brains. New York: W. W. Norton.

Gunter, B. , Rowlands, I. \& Nicholas, D. (2009). The Google Generation: Are ICT Innovations Changing Information Seeking Behaviour? Cambridge, UK: Chandos Publishing.

Kanter, J. \& Pfanner, E. (1 Dec 2010). Google Faces Antitrust Inquiry in Europe. New York Times, Late edition, p. B1.

Lohr, S. (13 Oct 2012). F.T.C. Said To Prepare For Lawsuit vs. Google. New York Times, New York edition, p. B1. 